\title{
Printed Circuit Board Fault Inspection Based on Eddy Current Testing Using Planar Coil Sensor
}

\author{
Socheatra Soeung ${ }^{1}$, Noohul Basheer Zain Ali $^{1}$, Mohd Haris Md Khir ${ }^{1} \&$ Arash Ahmadi $^{2}$ \\ ${ }^{1}$ Department of Electrical and Electronics Engineering, Universiti Teknologi PETRONAS, Tronoh, Malaysia \\ ${ }^{2}$ Department of Electrical Engineering, Razi University, Iran \\ Correspondence: Socheatra Soeung, Department of Electrical and Electronics engineering, Universiti Teknologi \\ PETRONAS, Tronoh, Malaysia. Tel: 60-14-9047-147. E-mail: socheatra@gmail.com
}

\author{
Received: January 6, $2014 \quad$ Accepted: February 27, $2014 \quad$ Online Published: March 14, 2014 \\ doi:10.5539/mas.v8n2p142 URL: http://dx.doi.org/10.5539/mas.v8n2p142
}

\begin{abstract}
This paper presents a printed circuit board (PCB) fault inspection method using eddy current testing generated from Helmholtz coils with a planar array-coil sensor to locate and inspect short and open faults on uniformly spaced interconnect single layer PCBs. The differences between the induced voltages from fault-free boards and faulty boards will be recorded in tables and translated into contour plots. The experimental results showed that in the presence of a short fault, the differences between the induced voltages from fault-free and faulty boards are highly negative. However, in the presence of an open fault, the differences between the induced voltages from fault free and faulty boards are highly positive. These highly positive or negative induced voltages can be translated into high density color regions on contour plots. The potential fault positions can be located by observing the color regions of the contour plots with respect to each element of the matrix sensor.
\end{abstract}

Keywords: eddy current testing, planar coil sensor, printed circuit board, fault inspection

\section{Introduction}

Testing is one of the important stages in the production of electronic products to ensure a fully functioning system. The reliability of PCBs affects the functionality of the devices on which they are mounted. The causes of electronic circuit failure are many, but they can be lumped into two possible categories: shorts and opens (Gizopoulos, 2006). To avoid components from getting damaged and further problems upon power up, the PCB must pass through fault inspection testing. Many testing techniques have been researched and developed for PCB (Benedek, Krammer, Janoczki, \& Jakab, 2013; Guifang, Hongcui, Zhenyu, \& Yen-Wei, 2012). However, they are either time consuming or not efficient (Enke \& Dagli, 1997). Visual methods are based on visual recognition processes which are limited to the inspection of the visible faults (Hara, Doi, Karasaki, \& Iida, 1988). Other methods such as reflected light method, automatic optic inspection, and image analysis have limitations when an image surface becomes dark and the density of the circuit is high (Hara, Akiyama, \& Karasaki, 1983; Shu-an \& Fenglin, 2011).

When a conductive material is placed close to an alternating magnetic field, there will be an oscillating electrical current induced in the conductive material due to Faraday's law of induction (Ulaby, 2005). These induced eddy currents will produce a secondary alternating magnetic field which is in the opposite direction to the original alternating magnetic field (Raj, Jayakumar, \& Thavasimuthu, 2007). The presence of any discontinuity or defect in the material will disturb the eddy current flow; hence, the secondary magnetic field will be disturbed. This disturbance can be detected as a voltage across a pick-up sensor which can be used to detect abnormality in the form of open and short faults on PCB traces.

Eddy current testing is a well-known method of non-destructive evaluation (NDE) that is applied to evaluate material flaws without changing or altering the material under test (Mukhopadhyay, 2005). Along with a variety of methods that include ultrasonic testing, dye penetrants and X-ray, eddy current testing is also commonly used for detecting fatigue cracks in conductive materials such as aircraft carriers and jet engines (Dogaru, C. Smith, Schneider, \& S. Smith, 2004; Grimberg, Udpa, Udpa, \& Savin, 2005; Uesaka et al., 1995). Recently, high frequency eddy current testing has been developed to detect micro defects on micro conductors of bare PCBs with various types of pick up sensors (Chomsuwan, Yamada, \& Iwahara, 2007a, 2007b; Chomsuwan, Yamada, 
Iwahara, Wakiwaka, \& Shoji, 2005; Kacprzak, Taniguchi, Nakamura, Yamada, \& Iwahara, 2001; Yamada et al., 2004; Yamada, Chomsuwan, Hagino, Tian, \& Iwahara, 2005; Yamada, Chomsuwan, \& Iwahara, 2006; Yamada, Nakamura, Iwahara, Taniguchi, \& Wakiwaka, 2003). In this paper, a low frequency eddy current testing probe structure is proposed which consists of Helmholtz coils exciter and a pick-up sensor made of 5 turn coils in planar array. The induced voltage of each array element is measured by Agilent multimeter. The resultant patterns are recorded in tabular form. The results from the fault free lines will then be used as the reference or ground truth values. Any voltage values which are high or low compared to the reference values will be defined as a potential fault on the PCB interconnect line.

\section{Proposed Eddy Current Testing Probe Structure}

In this research, a new design of ECT probe is constructed and used in detecting short and open faults on the PCB. The probe consists of a pair of Helmholtz coils, and a planar array-coil sensor. The planar array-coil sensor is fabricated on flame retardant 4 (FR4) board with thickness of $1.6 \mathrm{~mm}$ and copper cladding of $32 \mu \mathrm{m}$. This sensor is placed at $1.6 \mathrm{~mm}$ above the PCB trace and in the middle of a pair of Helmholtz coils. The sensor and the board under test are separated by FR4 substrate which acts as an insulator. The primary magnetic field generated by the pair of Helmholtz coils will cut through the PCB trace and induce eddy currents on the surface of the trace. The established eddy currents will circulate on the surface of the trace which further induces an alternating magnetic field perpendicular to the plane of the traces. The vertical magnetic field will cut through the axis of each element of the array-coil sensor. From the law of induction, an electrical current will flow through a conductor when a magnetic field cuts the conductor. Thus the voltage is induced across each coil. The induced voltages of the faulty and fault free lines are detected by the array-coil sensor. Any changes of eddy current due to a fault will introduce the changes of the induced voltage across the sensor. The detected induced voltage of each coil will be amplified and altered by the band pass filter. The induced voltages from each faulty line are compared to the induced voltage of the fault free lines. The altered output voltages will be recorded and used in fault inspection analysis to differentiate the faulty and non-faulty conductive lines. Figure 1 shows the front view of the proposed ECT probe used in PCB fault inspection.

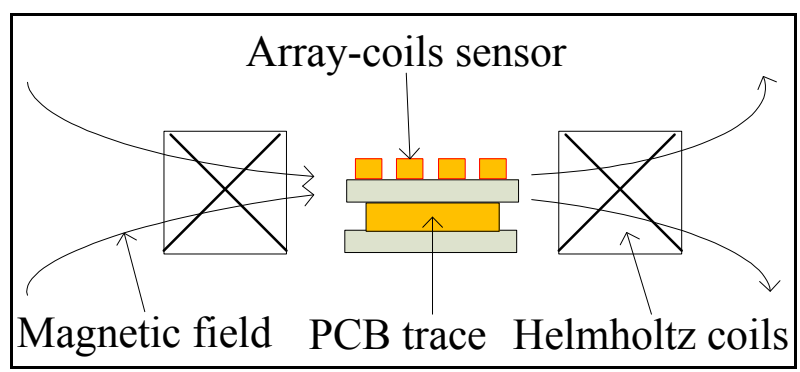

Figure 1. Front view of the proposed ECT probe

\section{Experimental Setup}

Figure 2 shows a block diagram of overall testing system. In this diagram there are a function generator, a pair of Helmholtz coils, devices under test (PCB and sensors), an amplifier circuit, a filter circuit, and a multi-meter. All the circuits are placed inside a magnetic chamber except the function generator and multi-meter. The pair of Helmholtz coils gets the sinusoidal signal supplied by the function generator at frequency of $800 \mathrm{~Hz}$. The primary induced magnetic field from Helmholtz coils cut through the PCB lines which are located in the middle of the pair of Helmholtz coils. The eddy current sensor is placed on top of the line under test. The induced output voltage detected by the sensor will be amplified by the instrumentation amplifier circuit which has a gain of 10 000. The circuit comes after the amplifier is the active band pass filter circuit which is used to filter signals from amplifier's output terminal. The filtered signals will be measured in RMS value in millivolt ranges.

The detail view of the fault inspection system setup is shown in Figure 3. In the box, there are the pair of Helmholtz coils, eddy current sensor, device under test, amplifier circuit, and active band pass filter circuit. Figure 4 shows the inside view of the shielded box which is used to improve precision of the system which is susceptible to the noise of magnetic field. 


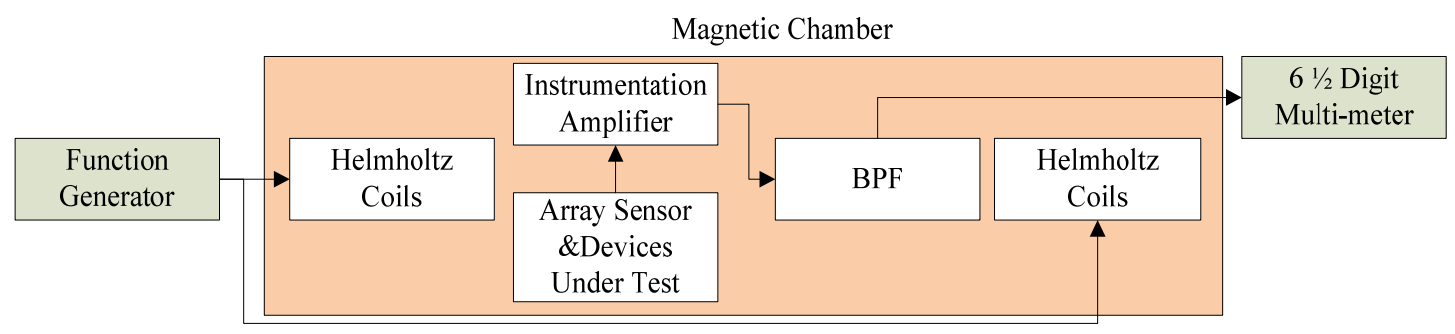

Figure 2. Testing system block diagram

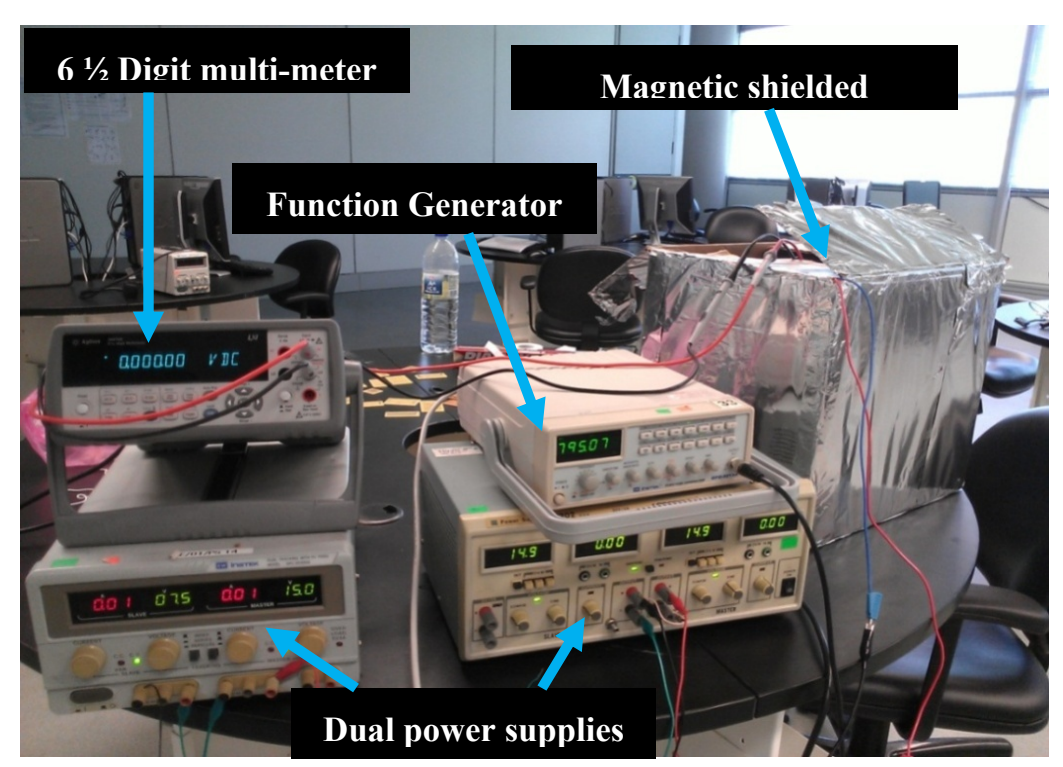

Figure 3. Overall system setup

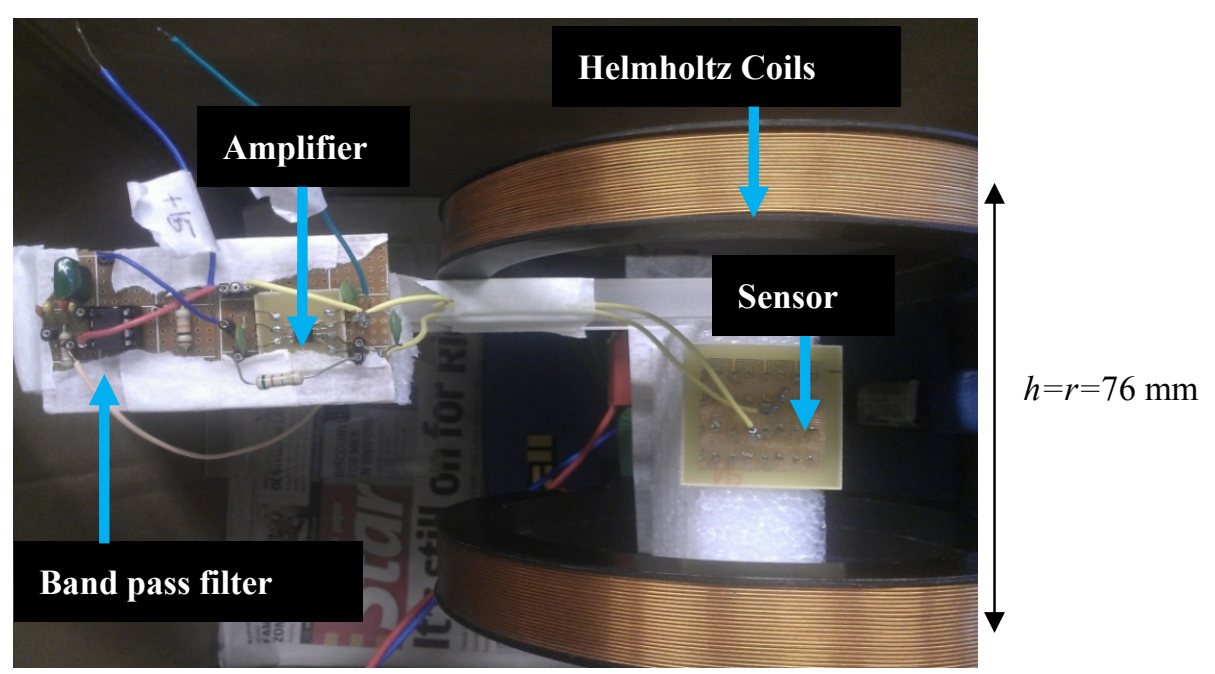

Figure 4. Inside view of shielded box

\subsection{Helmholtz Coils}

A Helmholtz coil is a wire-wound device that produces nearly uniform magnetic field. The magnetic field produced from a pair of Helmholtz coils can be obtained by using the following formula: 


$$
B=\left(\frac{4}{5}\right)^{\frac{3}{2}} \mu_{0} \frac{n I}{r}
$$

where $\mu_{0}=4 \pi \times 10^{-7} \mathrm{~T} \cdot \mathrm{m} / \mathrm{A}$ (permeability of free space), $n$ is the number of turns in each coil, $I$ is the current flows through each coil, $r$ is the radius of the coil. Table 1 describes the specification of each Helmholtz coil used in this work.

Table 1. Each Helmholtz coil parameters

\begin{tabular}{cc}
\hline Parameters & Values \\
\hline Maximum current $(l)$ & $2 \mathrm{~A}$ \\
Diameter of the wire & $0.71 \mathrm{~mm}$ \\
Number of turns $(n)$ & 320 \\
Length of wire in one loop $(l)$ & $0.478 \mathrm{~m}$ \\
Resistance $(R)$ & $6.64 \Omega$ \\
Radius $(r)$ & $76 \mathrm{~mm}$ \\
\hline
\end{tabular}

Equation (1) can be expressed in relation to input voltage as

$$
B=\left(\frac{4}{5}\right)^{\frac{3}{2}} \mu_{0} \frac{n V}{r R}
$$

Equation (2) can be obtained by applying Ohm's law to the current flowing through each coil of a resistor $R$ with voltage supply of $V$. The AC input voltage signal in millivolt at $800 \mathrm{~Hz}$ from function generator is applied to each coil to generate the uniform magnetic field density in the middle of both coils.

\subsection{Instrumentation Amplifier}

In this work the instrumentation amplifier, INA129 from Texas Instrument is selected due to its high voltage gain up to 10000 times, low power and good accuracy. It is placed right after the sensor in the fault inspection system. It is capable to amplify the sensor's output from microvolt ranges to millivolt ranges which can be read and observed clearly by the multi-meter. Its voltage gain, $A_{v}$ can be set by adjusting the value of $R_{\text {gain }}$ by the following formula

$$
G=1+\frac{49.4 k \Omega}{R_{G}}
$$

The maximum gain of this amplifier is 10000 with $R_{\text {gain }}$ equals to $4.94 \Omega$. The amplifier can be operated on power supplies ranging from $\pm 2.25 \mathrm{~V}$ to $\pm 18 \mathrm{~V}$. Within this range the amplifier performance remains in good operation. The power supply voltages of $\pm 15 \mathrm{~V}$ are chosen in order to obtain wider input linear range and bandwidth. At the highest gain of 10000 , its operation frequency bandwidth is $1 \mathrm{kHz}$. The input frequency is chosen to be $800 \mathrm{~Hz}$ to make sure the input voltage is within the operation frequency range.

\subsection{Active Bandpass Filter}

Active band pass filter is a cascade of a single high pass filter and a single low pass filter with the amplifier circuit in between. In active filter design, the amplification circuit is used to introduce gain and provide isolation between stages of filter. Under filter setup, the RC components of the band pass filter are calculated and its circuit is designed and simulated in PSpice. The band pass filter is designed with the center frequency of $800 \mathrm{~Hz}$, and voltage gain, $A v=1$. The following formulas are used to calculate the gain, $Q$-factors, and center frequency of the band pass filter.

$$
\begin{gathered}
A v=-\frac{R_{2}}{2 R_{1}}=-2 Q^{2} \\
Q=\frac{1}{2} \sqrt{\frac{R_{2}}{R_{1}}} \\
f_{c}=\frac{1}{2 \pi \sqrt{R_{1} R_{2} C_{1} C_{2}}}
\end{gathered}
$$


From (4), $Q=\sqrt{\frac{1}{2}}=0.7071$, and $R_{2}=2 R_{1}$. The resistors $R_{1}$ and $R_{2}$ are selected to be $10 \mathrm{k} \Omega$ and $20 \mathrm{k} \Omega$ respectively. The capacitor values can be achieved by assuming $C_{1}=C_{2}=C$. From (6), the capacitor values of the band pass filter circuit are $C_{1}=C_{2}=14 \mathrm{nF}$. The PSpice simulation result of band pass filter is shown in Figure 5 .

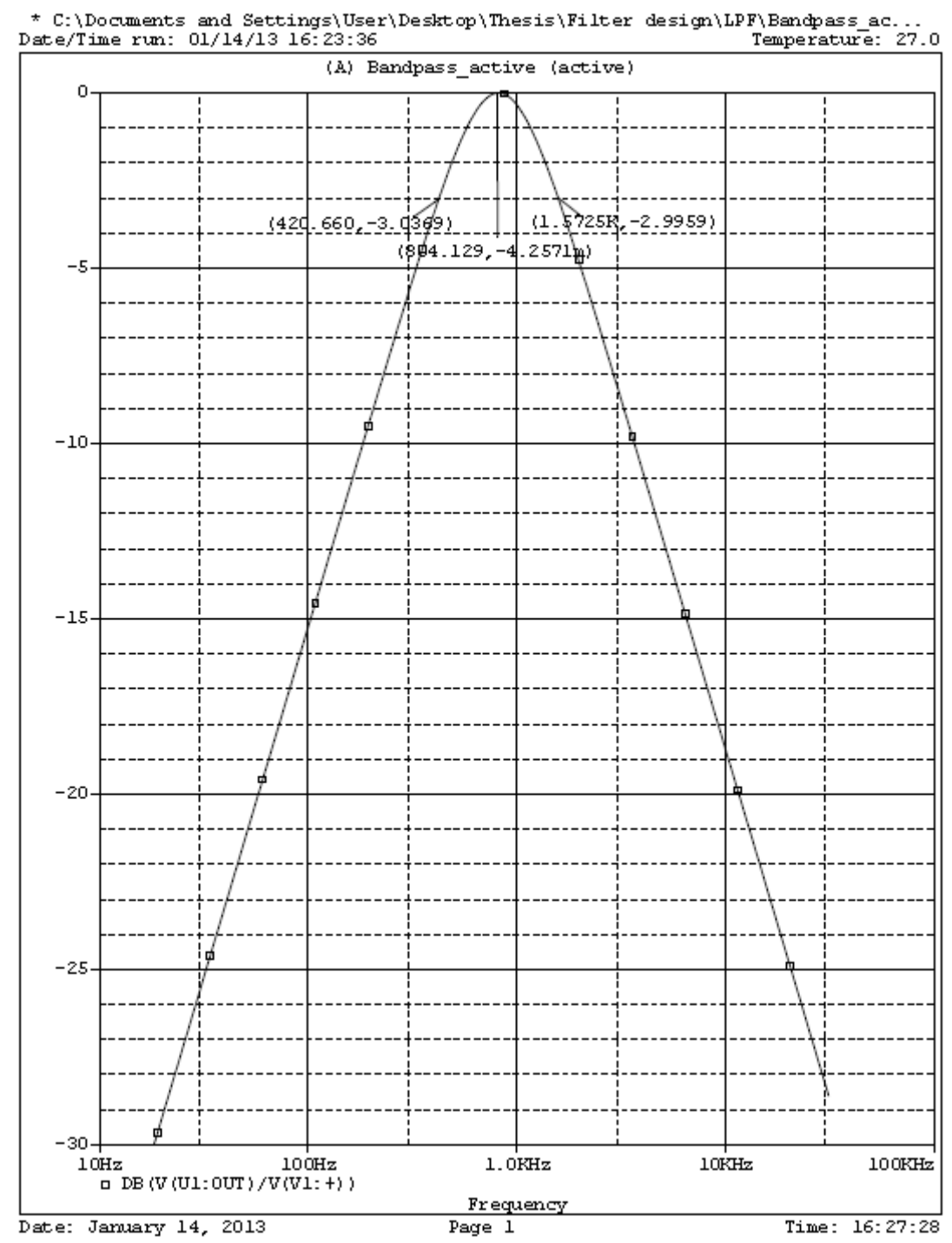

Figure 5. Band pass filter output response

Figure 5 shows that the band-pass filter at $-3 \mathrm{~dB}$ has the lower frequency at $420.6 \mathrm{~Hz}$ and the higher frequency at $1.572 \mathrm{kHz}$. The center frequency located at $804.129 \mathrm{~Hz}$ has the loss of $4.25 \mathrm{dBm}$. The multiple feedback band pass filter is designed with the low $Q$ factor to get wide bandwidth in order to pass wide range of the input frequency from the instrumentation amplifier. LM 358N operational amplifier is selected as the main component for the filter prototype. With the low power and wide bandwidth, this amplifier is suitable for multiple feedback active band pass filter design. The active band pass filter circuit configuration is realized as shown in Figure 6 . The multiple feedback band pass filter topology allows the designer to be able to adjust the $Q$ factor, and gain based on the values of resistors $R_{I}$ and $R_{2}$. Resistor $R_{3}$ in this design is used to adjust the center frequency without affecting the bandwidth and gain. However, for the low $Q$ factor the band pass filter can work without the resistor $R_{3}$. From the LM $358 \mathrm{~N}$ configuration the resistor $R_{3}$ can be selected as high input impedance of 10 $\mathrm{k} \Omega$ and the output capacitor is selected to be $10 C$ equal to $140 \mathrm{nF}$ to obtain a smooth filter output. The parameters for this active band pass filter configuration setup are listed in Table 2. 


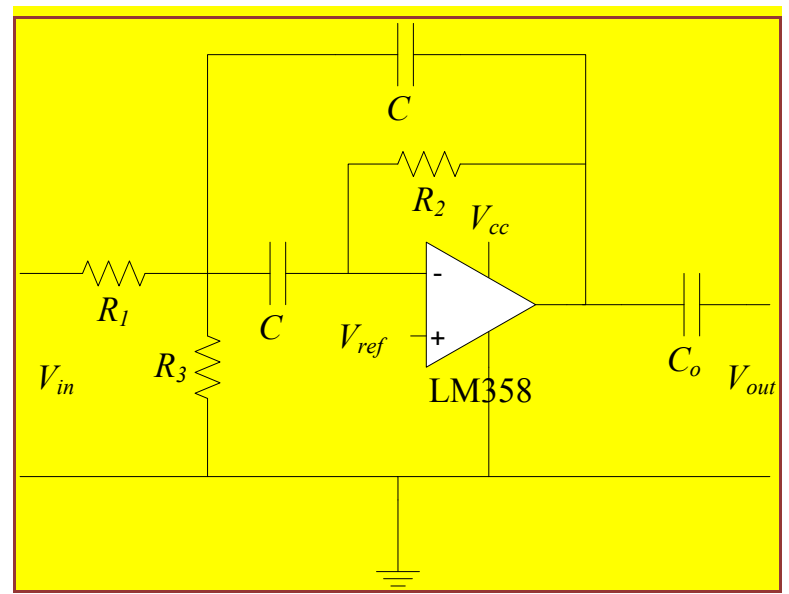

Figure 6. Active band pass filter configuration

Table 2. Active band pass filter parameters

\begin{tabular}{cc}
\hline Parameters & Values \\
\hline$R_{I}$ & $10 \mathrm{k} \Omega$ \\
$R_{2}$ & $20 \mathrm{k} \Omega$ \\
$R_{3}$ & $10 \mathrm{k} \Omega$ \\
$C$ & $14 \mathrm{nF}$ \\
$C_{0}$ & $140 \mathrm{nF}$ \\
$V_{c c}$ & $15 \mathrm{~V}$ \\
$V_{r e f}$ & $7.5 \mathrm{~V}$ \\
\hline
\end{tabular}

\subsection{Array-Coil Sensor Characterization}

This section focuses on the characterization of each element of the array-coil sensor. The matrix composes of 16 single coil sensors of 5 turns. The array-coil sensor is designed and fabricated on FR4 board. Figure 7 shows the array-coil sensor prototype of matrix 4 by 4 .

\section{$27.29 \mathrm{~mm}$}

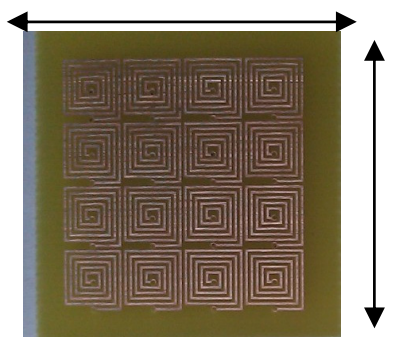

$27.9 \mathrm{~mm}$

Figure 7. Array-coil sensor of 4 by 4

The array-coil sensor characterization was conducted in the magnetic shielded box as shown in Figure 8 . The output induced voltage of each single coil sensor was amplified 10000 times by the instrumentation amplifier and filtered by the active band pass filter. These induced voltages were recorded by the multimeter. The sensitivity $(\mu \mathrm{V} / \mathrm{mT})$ of each coil can be achieved by dividing the induced output voltage by the magnetic field density $(B)$ that cuts through each coil. From this, each coil's sensitivity is defined as:

$$
\text { Sensitivity }=\frac{V_{\text {induced }}}{10000 \times B}
$$




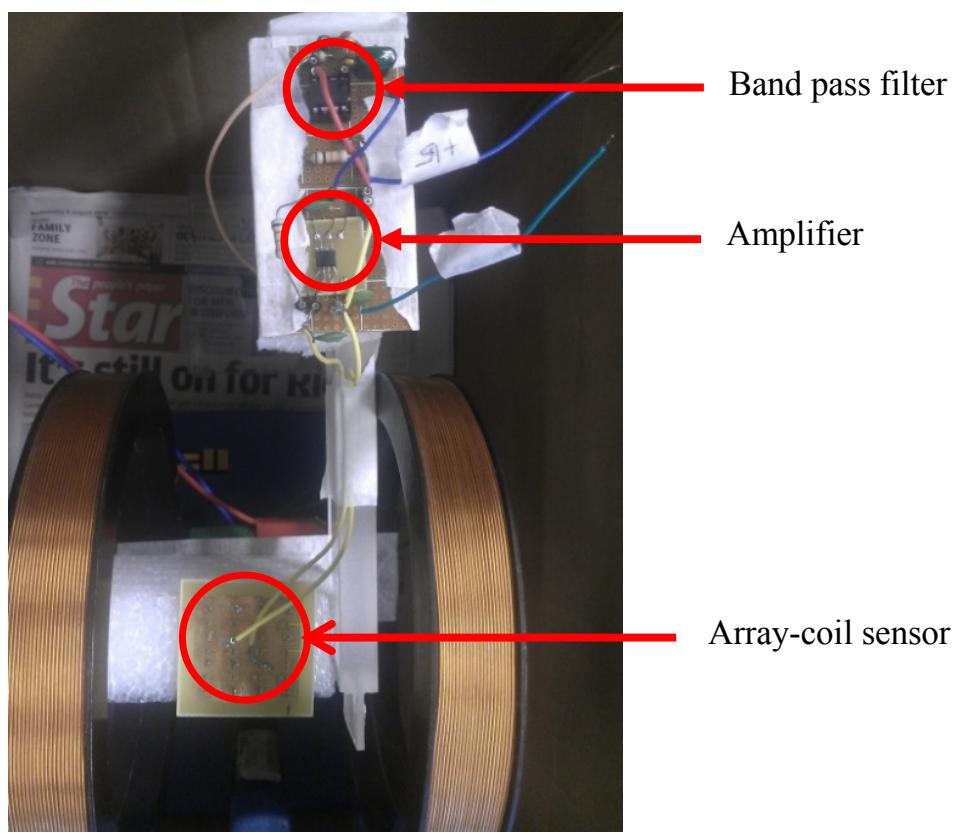

Figure 8. Array-coil sensors inside magnetic shielding box

The sensitivities of each element of array-coil sensor are recorded in Table 3. Each row and column from Table 3 represents each element of the matrix sensor. From Table 3, each element's sensitivity in the same row is approximately close to each other. However, the sensitivity of the array-coil sensor drops from the $1^{\text {st }}$ to the $4^{\text {th }}$ row. This is due to the arrangement of array-coil sensor position, extra length of connectors or jumpers, and additional magnetizing conductive material on the board. The change in sensitivity may be due to the changes in area and shape of the jumpers which are connected from each element to the amplifier. It can be concluded that the sensitivity of the sensor is easily affected by the additional area created by external conductive wires or jumpers. Therefore, all the component parameters used in the array-coil sensor characterization are fixed in order to obtain optimal PCB fault inspection results.

Table 3. Array-coil sensor's sensitivity

\begin{tabular}{|c|c|c|c|}
\hline \multicolumn{4}{|c|}{4 by 4 array-coil sensitivity $(\mu \mathrm{V} / \mathrm{mT})$} \\
\hline 0.74 & 0.72 & 0.76 & 0.81 \\
\hline 0.62 & 0.61 & 0.57 & 0.62 \\
\hline 0.52 & 0.57 & 0.61 & 0.51 \\
\hline 0.41 & 0.41 & 0.48 & 0.42 \\
\hline
\end{tabular}

\subsection{PCB Inspection Setup}

Having modeled and simulated PCB lines and eddy current sensor in Computer Simulation Technology (CST), the PCB design layouts from Advanced System Design (ADS) were sent for fabrication on FR4 board. Three sets of PCB lines have been fabricated for normal, opened and shorted lines. These boards were passed through ECT to inspect the changing induced voltage patterns in the conditions of faulty and fault-free and to locate the potential fault on the lines. Figure 9 and Figure 10 show the PCB normal line prototypes on FR4 boards. The PCB lines have been fabricated in two types of width; $300 \mu \mathrm{m}$ and $600 \mu \mathrm{m}$ with different line spacing of $4 \mathrm{~mm}$, $2 \mathrm{~mm}$ and $1 \mathrm{~mm}$. 

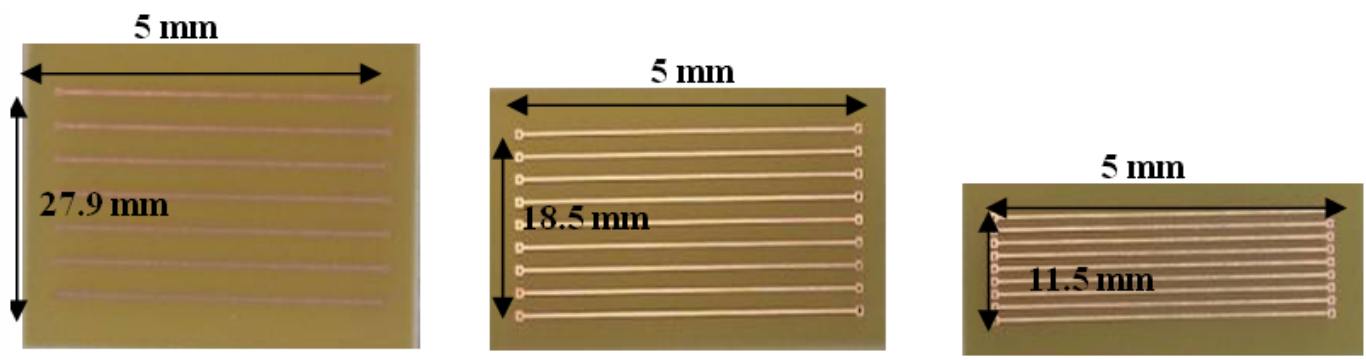

Figure 9. Line width $=300 \mu \mathrm{m}$ and the line to line distance of $4 \mathrm{~mm}, 2 \mathrm{~mm}$ and $1 \mathrm{~mm}$ respectively
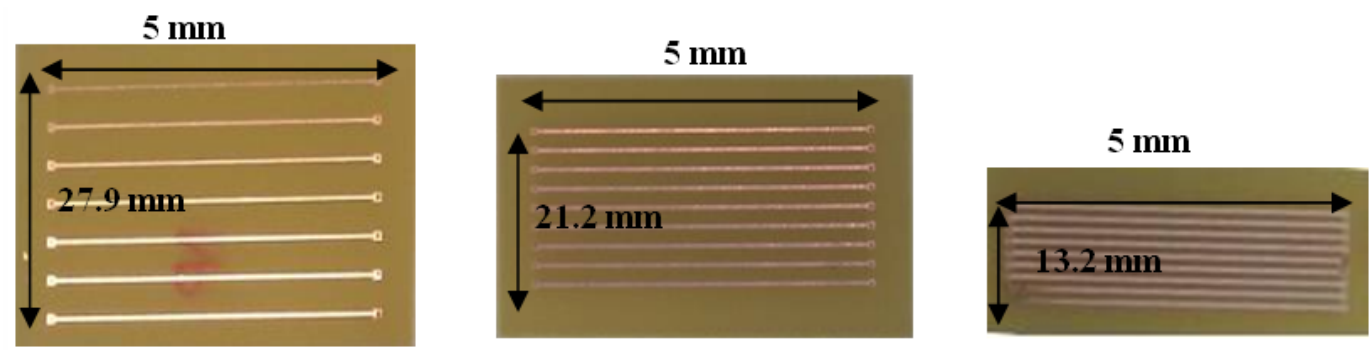

Figure 10. Line width $=600 \mu \mathrm{m}$ and the line to line distance of $4 \mathrm{~mm}, 2 \mathrm{~mm}$ and $1 \mathrm{~mm}$ respectively

The fabricated PCB lines shown in Figure 9 and Figure 10 have been inspected under three conditions: fault free, single fault at a time and two faults at a time. The array-coil sensor of 4 by 4 , composed of single coil sensors of 5 turns, is placed on the top of each PCB. Figure 11 and Figure 12 displays the six fault free boards with the array-coil sensors lay on top of each board. A single coil sensor element can cover at most 5 lines, 3 lines, and 2 lines for the line spacing of $1 \mathrm{~mm}, 2 \mathrm{~mm}$, and $4 \mathrm{~mm}$, respectively.
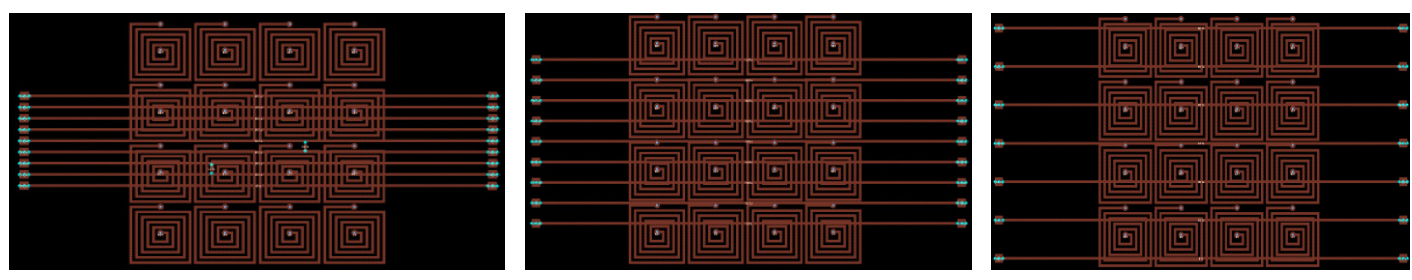

Figure 11. Line width $=300 \mu \mathrm{m}$ and line to line distance of $1 \mathrm{~mm}, 2 \mathrm{~mm}$ and $4 \mathrm{~mm}$ respectively
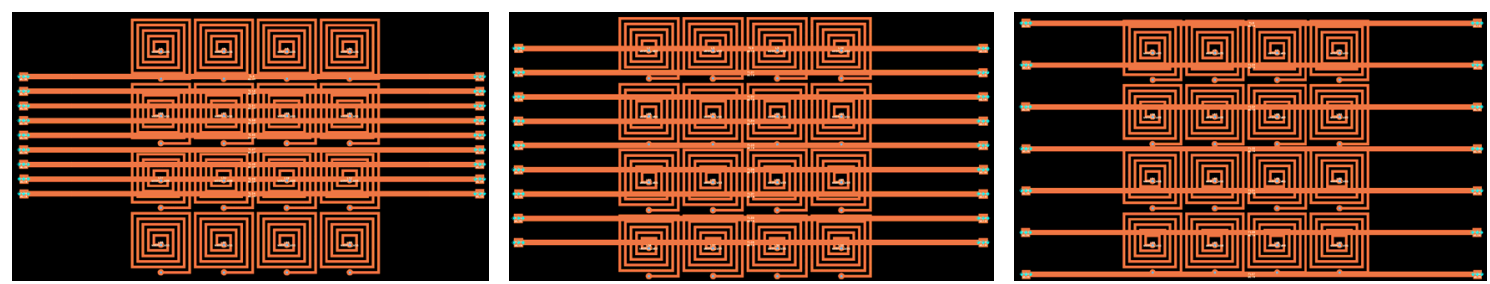

Figure 12. Line width=600 $\mu \mathrm{m}$ and line to line distance of $1 \mathrm{~mm}, 2 \mathrm{~mm}$ and $4 \mathrm{~mm}$ respectively

A single fault at a time and two faults at a time are injected to the fault free PCB lines of Figure. The two types of fault are short and open. For a single fault at a time, it occurs on the third and fourth lines for the short fault and the third line for the open fault. In addition to a single fault at a time, two faults at a time have an extra fault located on the fifth and sixth lines for the short fault and the sixth line for the open fault. The PCB fault injection on the PCB lines is shown in Figure 13. 


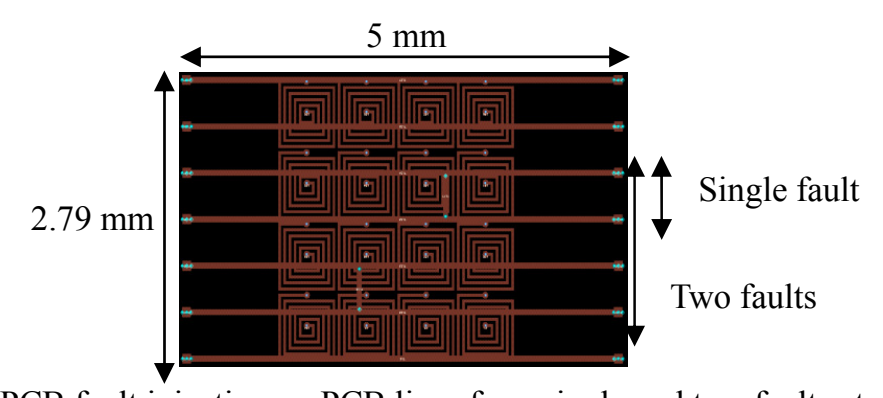

Figure 13. PCB fault injection on PCB lines for a single and two faults at a time

\section{Experimental Results}

Each of the above setup boards is placed in the middle of a pair of Helmholtz coils. The PCB lines were exposed to an alternating magnetic field generated by the pair of Helmholtz coils. In the presence of the alternating magnetic field, eddy currents are induced on the conductive lines. These eddy currents induce an alternating magnetic field perpendicular to the PCB lines. This field cut through the axis of the array-coil sensor which was placed at $1.6 \mathrm{~mm}$ above the PCB lines. The induced voltage values from every element of the array-coil sensors were amplified and filtered before recording. The output signals were measured in RMS. In this experiment, each board along with the array-coil sensor produces a 4 by 4 induced voltage matrix. The six induced voltage matrices under the same testing condition were summarized in one table. The records of the induced voltages from all reference boards (fault-free) were used as reference voltages compared to the induced voltages from the faulty (short and open) boards. Each board is tested for more than three times in order to get the average induced voltages. The average values of the induced voltages were displayed in tables and used throughout the fault analysis process.

Having been discussed in Section 3.5, the reference or the normal boards were assumed to be fault free boards. Firstly, the fault free boards were inspected and the output induced voltages were recorded. Secondly, the single fault inspection was conducted and the output induced voltages were recorded. Thirdly, the two faults at a time inspection was experimented and the output induced voltages were recorded. Lastly, these recorded output voltages were analyzed to generate patterns to differentiate between faulty and fault free boards and to locate the potential fault on the lines.

\subsection{Ground Truth Reference}

The boards in Figure 9 and Figure 10 were used as the reference boards (fault-free boards). The induced voltages from these boards were tested and recorded for several times until encouraging results were obtained before proceeding further for PCB inspection. While the calibration of the testing system was done, the inspection on fault free boards would be conducted at least three times. The induced voltages from each board were recorded in three tables. These tables were used to obtain the table of the average induced voltage values. The average induced voltage values from each board were used as the ground truth data or reference values in order to do fault analysis patterns to differentiate between faulty boards and fault free boards. Table 4 provides the first, second, and third reference boards testing results and the average induced voltages from the three testing results. 
Table 4. Average induced voltages for reference (fault free) boards

\begin{tabular}{|c|c|c|c|c|c|c|c|c|c|c|c|c|}
\hline \multicolumn{13}{|c|}{ First test } \\
\hline \multirow{2}{*}{ Line width } & \multicolumn{12}{|c|}{$4 \times 4$ Array-coil sensor with $N=5$ turns } \\
\hline & \multicolumn{4}{|c|}{ Line Space $=1 \mathrm{~mm}(\mathrm{mV})$} & \multicolumn{4}{|c|}{ Line Space $=2 \mathrm{~mm}(\mathrm{mV})$} & \multicolumn{4}{|c|}{ Line Space = $4 \mathrm{~mm}(\mathrm{mV})$} \\
\hline \multirow{4}{*}{$300 \mu \mathrm{m}$} & 150 & 230 & 218 & 161 & 154 & 142 & 190 & 184 & 126 & 162 & 187 & 175 \\
\hline & 145 & 223 & 154 & 136 & 123 & 151 & 126 & 150 & 163 & 162 & 115 & 112 \\
\hline & 126 & 113 & 167 & 122 & 126 & 138 & 137 & 121 & 134 & 131 & 177 & 131 \\
\hline & 136 & 142 & 167 & 168 & 133 & 140 & 151 & 153 & 117 & 101 & 122 & 129 \\
\hline \multirow{4}{*}{$600 \mu \mathrm{m}$} & 201 & 234 & 226 & 232 & 165 & 244 & 237 & 227 & 161 & 355 & 233 & 248 \\
\hline & 230 & 237 & 213 & 183 & 158 & 210 & 242 & 161 & 135 & 247 & 103 & 141 \\
\hline & 109 & 132 & 220 & 134 & 116 & 164 & 236 & 159 & 134 & 126 & 226 & 177 \\
\hline & 171 & 138 & 154 & 125 & 98 & 106 & 106 & 133 & 119 & 110 & 109 & 131 \\
\hline \multicolumn{13}{|c|}{ Second test } \\
\hline \multirow{2}{*}{ Line width } & \multicolumn{12}{|c|}{$4 \times 4$ Array-coil sensor with $N=5$ turns } \\
\hline & \multicolumn{4}{|c|}{ Line Space $=1 \mathrm{~mm}(\mathrm{mV})$} & \multicolumn{4}{|c|}{ Line Space $=2 \mathrm{~mm}(\mathrm{mV})$} & \multicolumn{4}{|c|}{ Line Space $=4 \mathrm{~mm}(\mathrm{mV})$} \\
\hline \multirow{4}{*}{$300 \mu \mathrm{m}$} & 180 & 215 & 196 & 210 & 212 & 207 & 216 & 199 & 150 & 192 & 195 & 202 \\
\hline & 170 & 185 & 155 & 145 & 179 & 190 & 142 & 156 & 118 & 174 & 146 & 156 \\
\hline & 126 & 145 & 175 & 123 & 142 & 165 & 145 & 136 & 129 & 176 & 152 & 164 \\
\hline & 150 & 128 & 127 & 155 & 100 & 125 & 136 & 138 & 159 & 142 & 140 & 157 \\
\hline \multirow{4}{*}{$600 \mu \mathrm{m}$} & 168 & 214 & 210 & 196 & 187 & 194 & 218 & 198 & 191 & 178 & 153 & 189 \\
\hline & 178 & 198 & 180 & 174 & 194 & 186 & 146 & 132 & 125 & 190 & 176 & 128 \\
\hline & 150 & 145 & 150 & 121 & 150 & 140 & 155 & 120 & 125 & 150 & 142 & 120 \\
\hline & 123 & 124 & 162 & 155 & 115 & 140 & 130 & 160 & 125 & 111 & 105 & 140 \\
\hline \multicolumn{13}{|c|}{ Third test } \\
\hline \multirow{2}{*}{ Line width } & \multicolumn{12}{|c|}{$4 \times 4$ Array-coil sensor with $N=5$ turns } \\
\hline & \multicolumn{4}{|c|}{ Line Space $=1 \mathrm{~mm}(\mathrm{mV})$} & \multicolumn{4}{|c|}{ Line Space $=2 \mathrm{~mm}(\mathrm{mV})$} & & e Spac & $\mathrm{mm}(\mathrm{n}$ & \\
\hline & 174 & 194 & 186 & 191 & 179 & 185 & 200 & 178 & 132 & 186 & 200 & 195 \\
\hline 200 um & 162 & 156 & 132 & 139 & 187 & 184 & 155 & 135 & 118 & 165 & 132 & 143 \\
\hline & 132 & 132 & 168 & 127 & 134 & 165 & 138 & 124 & 142 & 176 & 160 & 140 \\
\hline & 143 & 135 & 156 & 145 & 126 & 125 & 130 & 144 & 159 & 135 & 140 & 149 \\
\hline & 189 & 212 & 215 & 205 & 191 & 204 & 199 & 220 & 182 & 178 & 184 & 208 \\
\hline 600 um & 183 & 189 & 180 & 174 & 194 & 198 & 176 & 139 & 145 & 190 & 159 & 130 \\
\hline 000 माп & 140 & 152 & 155 & 123 & 148 & 134 & 170 & 156 & 125 & 150 & 142 & 126 \\
\hline & 132 & 131 & 164 & 125 & 120 & 120 & 130 & 142 & 125 & 131 & 110 & 140 \\
\hline & & & & & & verag & & & & & & \\
\hline Iin ovid th & & & & & Array & ens or & $\mathrm{N}=5 \mathrm{t}$ & Refer & & & & \\
\hline Line Watn & & ne Spa & $\mathrm{mm}(\mathrm{m}$ & & & e Spa & $\mathrm{mm}(\mathrm{n}$ & & & ne Spa & $\mathrm{mm}(\mathrm{r}$ & \\
\hline & 162 & 213 & 200 & 172 & 163 & 178 & 202 & 187 & 136 & 165 & 194 & 175 \\
\hline $300 \mu$ & 159 & 188 & 147 & 140 & 163 & 175 & 141 & 147 & 133 & 167 & 131 & 137 \\
\hline & 128 & 130 & 170 & 124 & 134 & 156 & 140 & 127 & 135 & 161 & 163 & 145 \\
\hline & 143 & 135 & 150 & 156 & 128 & 130 & 139 & 145 & 145 & 126 & 134 & 145 \\
\hline & 186 & 220 & 217 & 211 & 181 & 214 & 218 & 215 & 178 & 237 & 190 & 215 \\
\hline 600 um & 197 & 208 & 191 & 177 & 182 & 198 & 188 & 144 & 135 & 209 & 146 & 133 \\
\hline обо нाп & 133 & 143 & 175 & 126 & 138 & 146 & 187 & 145 & 128 & 142 & 170 & 141 \\
\hline & 142 & 131 & 160 & 135 & 111 & 122 & 122 & 145 & 123 & 110 & 108 & 137 \\
\hline
\end{tabular}

\subsection{Single Fault Inspection}

Table 5 presents the difference between the induced voltages detected by each element of the array-coil sensor from the fault free boards and a single short fault boards. 
Table 5. Difference of the induced voltages from the fault free and single short fault boards

\begin{tabular}{|c|c|c|c|c|c|c|c|c|c|c|c|c|}
\hline \multirow{2}{*}{$\begin{array}{c}\text { Line } \\
\text { width }\end{array}$} & \multicolumn{12}{|c|}{$4 \times 4$ Array-coil sensor with $N=5$ turns (Ref- Short) } \\
\hline & \multicolumn{4}{|c|}{ Line Space $=1 \mathrm{~mm}(\mathrm{mV})$} & \multicolumn{4}{|c|}{ Line Space $=2 \mathrm{~mm}(\mathrm{mV})$} & \multicolumn{4}{|c|}{ Line Space $=4 \mathrm{~mm}(\mathrm{mV})$} \\
\hline \multirow{4}{*}{$300 \mu \mathrm{m}$} & 2 & 15 & 11 & -1 & 13 & -15 & -8 & -20 & -1 & 0 & -6 & 3 \\
\hline & 31 & -5 & 0 & -2 & -8 & -48 & -12 & -9 & -11 & -27 & -25 & -9 \\
\hline & -31 & -70 & -20 & -1 & -23 & -29 & -28 & 0 & -7 & -41 & -26 & -16 \\
\hline & 8 & -17 & -13 & 1 & -1 & -13 & -11 & 10 & 9 & -14 & -16 & 6 \\
\hline \multirow{4}{*}{$600 \mu \mathrm{m}$} & 4 & 10 & -8 & -4 & -1 & -12 & -5 & -6 & -19 & 7 & -15 & 13 \\
\hline & -3 & -20 & 1 & -4 & -12 & 4 & -3 & -16 & -32 & -3 & -3 & -4 \\
\hline & -27 & -47 & -36 & -20 & -19 & -34 & -35 & 0 & -3 & -30 & -10 & 1 \\
\hline & 2 & -14 & 10 & -12 & -39 & -31 & -5 & -16 & 2 & -14 & -6 & -10 \\
\hline
\end{tabular}

The highlighted elements have negative voltage values of higher than $30 \mathrm{mV}$. They are defined as the high resultant voltage values and a high potential location of a short fault occurrence on the lines which could be covered and observed by that element of the matrix. In the presence of a single short fault, higher induced voltages occur around the defect point compared to the fault free lines. This leads to a strong difference in the negative values in the matrix shown in the above Table 5. The matrices in Table 5 can be represented by the contour plots to clearly display and locate the defect point detected by the elements of the array-coil sensor. Figure 14 illustrates the contour plots of each matrix. The contour plots are obtained from MATLAB software. In Figure 14, the star shape on each contour plot represents the real physical fault location with respect to the matrix element. The negatively resulted induced voltage between the normal lines and short lines are displayed in the color ranges from light blue to dark color regions. From these plots, the array-coil sensor is able to locate the potential position of the single short fault. The fault can be clearly located at the highly negative voltage of the element of row 3, column 2 .

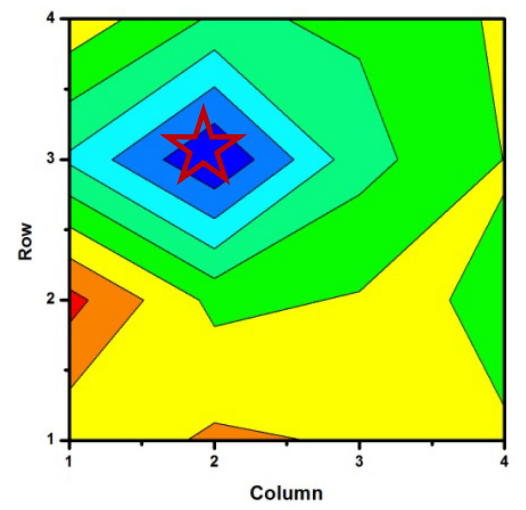

(a)

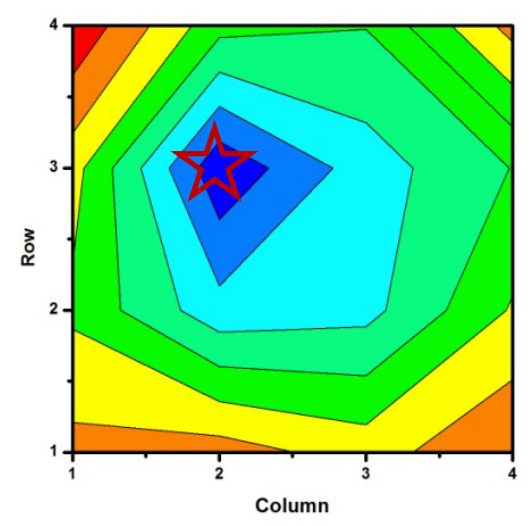

(c)
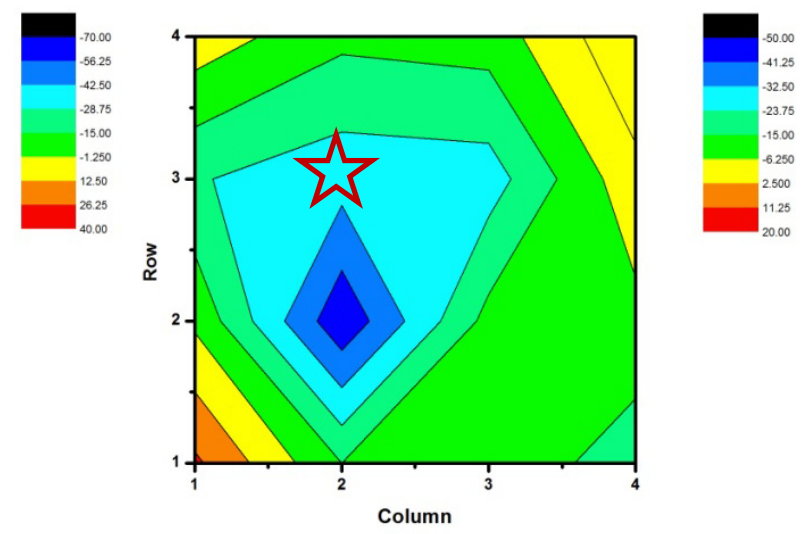

(b)
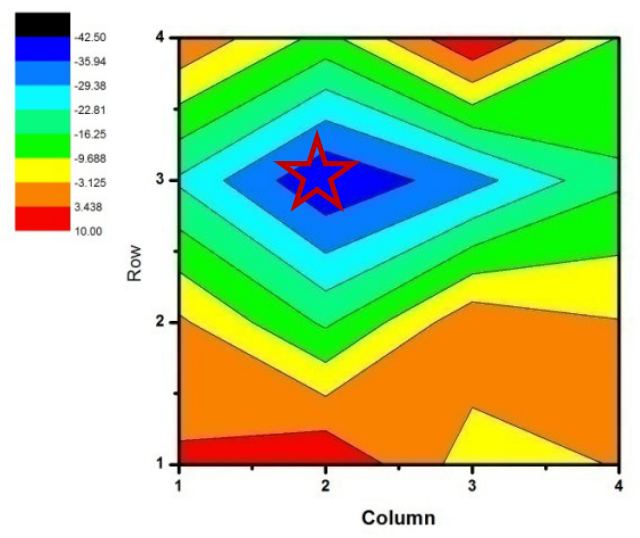

(d) 


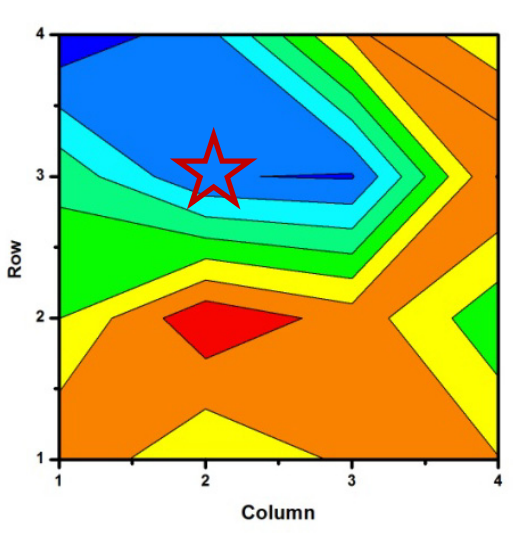

(e)

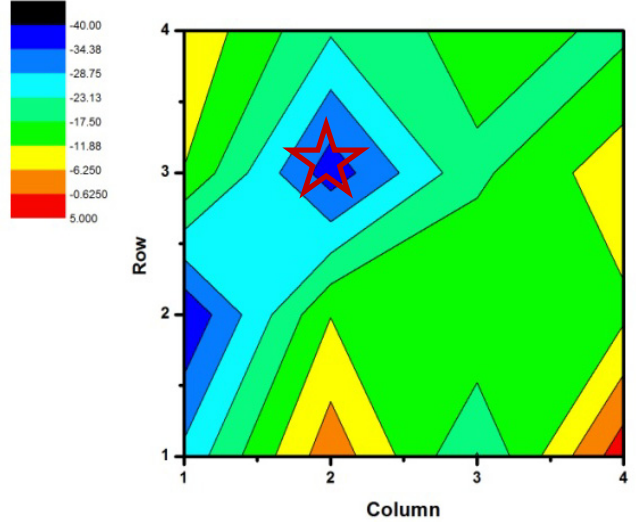

(f)

Figure 14. Contour map of the difference of the induced voltages between the fault free and single short fault boards: the lines of the width of $300 \mu \mathrm{m}$ : (a) $1 \mathrm{~mm}$, (b) $2 \mathrm{~mm}$ and (c) $4 \mathrm{~mm}$ line spaces and the lines of the width of $600 \mu \mathrm{m}$, (d) $1 \mathrm{~mm}$, (e) $2 \mathrm{~mm}$ and (f) $4 \mathrm{~mm}$ line spaces

The next observation is on the single open defect on the conductive lines. Table 6 shows the record of the difference between the induced voltages from the normal lines and the single open fault lines.

Table 6. Difference of the induced voltages from the fault free and single open fault boards

\begin{tabular}{|c|c|c|c|c|c|c|c|c|c|c|c|c|}
\hline \multirow{2}{*}{$\begin{array}{l}\text { Line } \\
\text { width }\end{array}$} & \multicolumn{12}{|c|}{$4 \times 4$ Array-coil sensor with $N=5$ turns (Ref-Open) } \\
\hline & \multicolumn{4}{|c|}{ Line Space $=1 \mathrm{~mm}(\mathrm{mV})$} & \multicolumn{4}{|c|}{ Line Space $=2 \mathrm{~mm}(\mathrm{mV})$} & \multicolumn{4}{|c|}{ Line Space $=4 \mathrm{~mm}(\mathrm{mV})$} \\
\hline \multirow{4}{*}{$300 \mu \mathrm{m}$} & 5 & -9 & -5 & -23 & -7 & 3 & 9 & -7 & 9 & 9 & -16 & 4 \\
\hline & 24 & 19 & 20 & -28 & 30 & 33 & 13 & 23 & 11 & 36 & 21 & 12 \\
\hline & 28 & 23 & 26 & 17 & 29 & 34 & 11 & 11 & 30 & 48 & 41 & 12 \\
\hline & 22 & 15 & 23 & 36 & 3 & 18 & 29 & 25 & 18 & 4 & -6 & 3 \\
\hline \multirow{4}{*}{$600 \mu \mathrm{m}$} & -12 & -5 & 2 & 28 & 5 & -10 & -8 & -3 & 0 & 11 & -16 & -2 \\
\hline & 17 & 26 & 45 & 26 & 52 & 53 & 43 & 14 & -3 & 17 & -5 & -7 \\
\hline & 19 & 19 & 25 & 21 & 20 & 38 & 56 & 35 & 18 & 37 & 35 & 18 \\
\hline & 11 & 15 & 42 & 8 & 21 & 2 & 8 & 15 & 23 & -8 & 3 & 15 \\
\hline
\end{tabular}

From Table 6 it can be seen that the single open defect induced a lower voltage as compared to the normal lines. As a result, the difference of the induced voltage varies from the fault free lines and a single open defect line is highly positive in its values. These highly positive values which are greater than $30 \mathrm{mV}$ are highlighted. The first matrix from PCB line width of $300 \mu \mathrm{m}$ with the line spacing of $1 \mathrm{~mm}$ shows the high positive values located on the middle elements. This means that there is a possible fault occurrence on the line which is covered by the 2 nd and 3rd row of the sensor. The location of the single open fault can be located around those highlighted elements. These matrices have been translated in the contour plots to ease the single open fault observation as shown in Figure 15. The plots have shown the highly positive color regions ranging from orange to red color. The star shape shows the superimposing of the real physical open fault onto each map. From these maps, not all the real physical open fault location can be observed. Only Figure 15 (b), 15 (c) and 15 (f) have shown the correct location of the single open fault with respect to its real physical location. The errors in determining the potential location of the fault are due to error in injecting the open fault on the line and strong coupling between the lines near to the opened line. As a result, a wide area of highly positive region can be observed on each plot. 


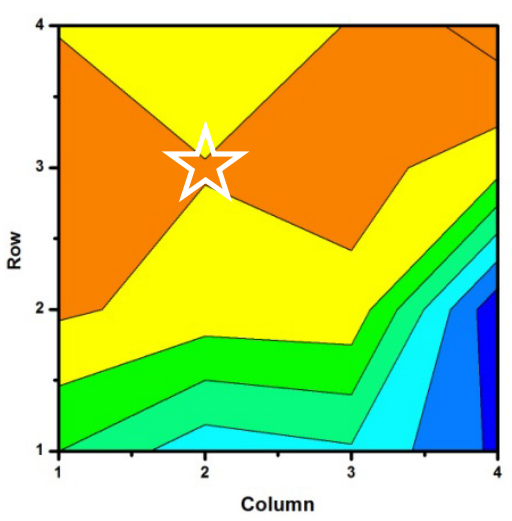

(a)

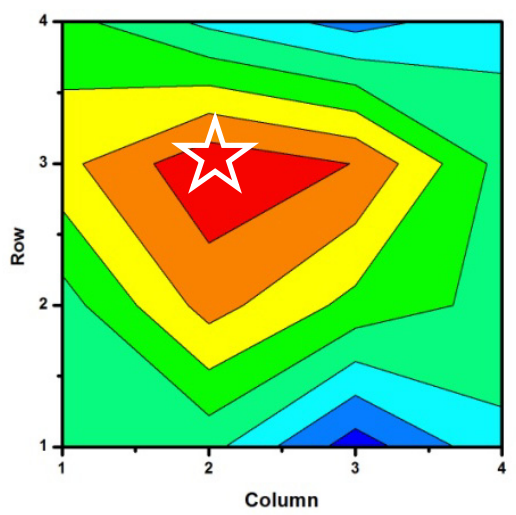

(c)

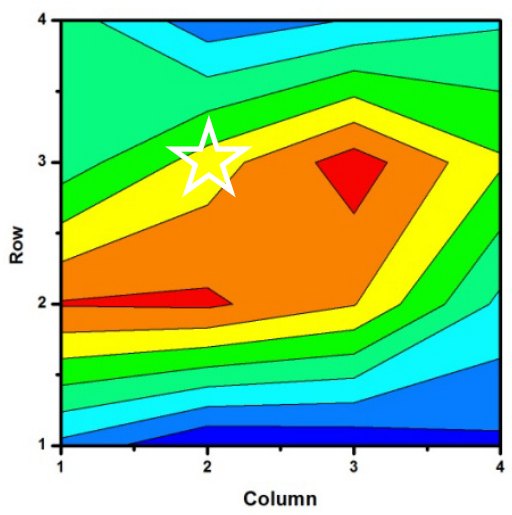

(e)

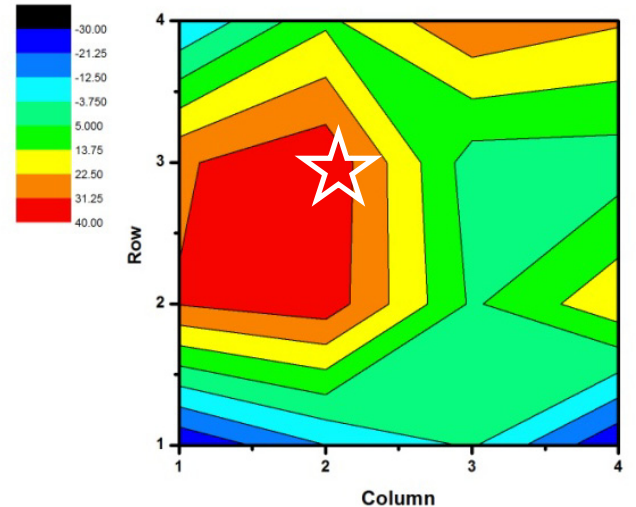

(b)
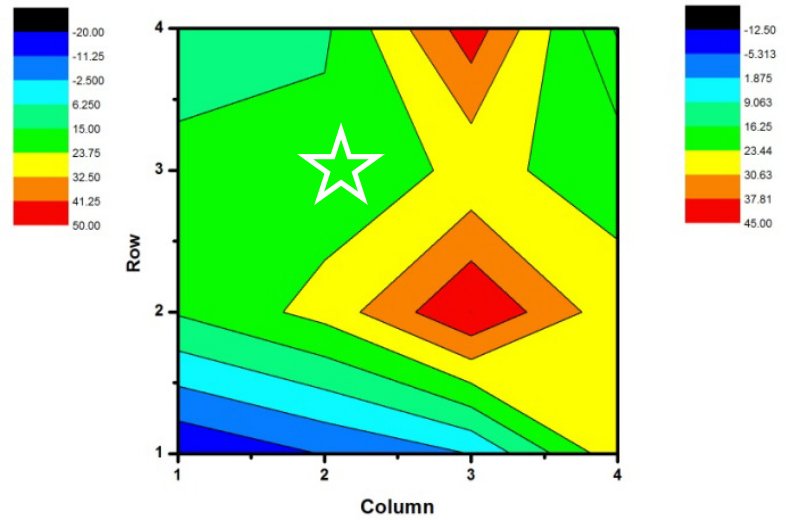

(d)
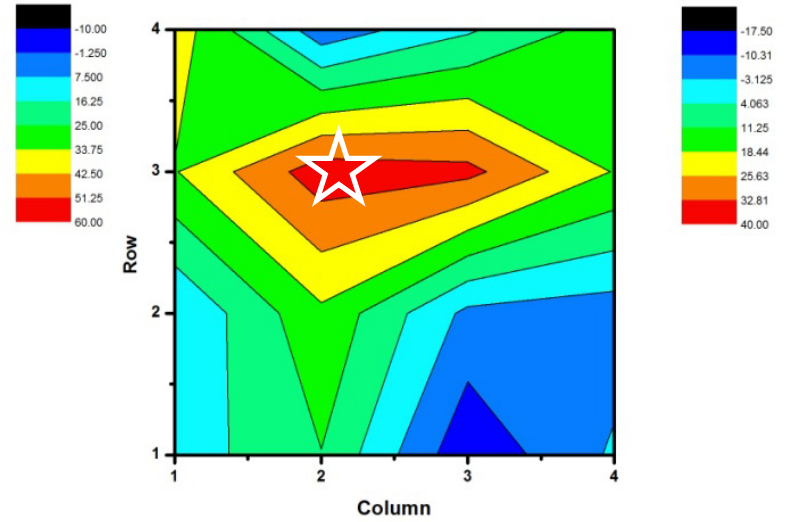

(f)

Figure15. Contour map of the difference induced voltages between the fault free and single open fault boards: the lines of the width $300 \mu \mathrm{m}$, (a) $1 \mathrm{~mm}$, (b) $2 \mathrm{~mm}$ and (c) $4 \mathrm{~mm}$ line spaces and the lines of the width $600 \mu \mathrm{m}$ : (d) $1 \mathrm{~mm}$, (e) $2 \mathrm{~mm}$ and (f) $4 \mathrm{~mm}$ line spaces

\subsection{Double Fault Inspection}

In this inspection, two pairs of shorted lines are experimented on the same board. The array-coil sensor is used to detect the changes of the induced voltages from the boards. Table 7 shows the difference between the induced voltages from the reference lines and the two short faults on the lines. 
Table 7. Difference of the induced voltages from fault free and two short faults boards

\begin{tabular}{|c|c|c|c|c|c|c|c|c|c|c|c|c|}
\hline \multirow{2}{*}{$\begin{array}{c}\text { Line } \\
\text { width }\end{array}$} & \multicolumn{12}{|c|}{$4 \times 4$ Array-coil sens or with $N=5$ turns (Ref- Short) for 2 short defects } \\
\hline & \multicolumn{4}{|c|}{ Line Space $=1 \mathrm{~mm}(\mathrm{mV})$} & \multicolumn{4}{|c|}{ Line Space $=2 \mathrm{~mm}(\mathrm{mV})$} & \multicolumn{4}{|c|}{ Line Space $=4 \mathrm{~mm}(\mathrm{mV})$} \\
\hline \multirow{4}{*}{$300 \mu \mathrm{m}$} & -18 & -8 & -12 & -8 & -37 & -47 & -21 & -39 & -6 & -4 & -33 & -31 \\
\hline & -35 & -64 & -40 & -61 & -29 & -47 & -95 & -67 & -9 & -76 & -74 & -35 \\
\hline & -14 & -65 & -40 & -9 & -18 & -46 & -52 & -2 & -1 & -53 & -10 & 8 \\
\hline & 8 & 2 & 14 & -6 & 4 & -22 & 6 & 10 & 15 & -4 & -15 & -2 \\
\hline \multirow{4}{*}{$600 \mu \mathrm{m}$} & -14 & -10 & -10 & -27 & -16 & -39 & -62 & -58 & -25 & -40 & -66 & -15 \\
\hline & -12 & -24 & -59 & 4 & 0 & -44 & -35 & -19 & -30 & -21 & -46 & -4 \\
\hline & -17 & -37 & -36 & -4 & -8 & -46 & -27 & 5 & -26 & -41 & -43 & -12 \\
\hline & -23 & -20 & 10 & -5 & -8 & -35 & -23 & 7 & -5 & -20 & -30 & -13 \\
\hline
\end{tabular}

In Table 7, there are many highly negative values detected by the elements of the array-coil sensor compared to the inspection of single fault at a time. The potential fault locations can be found by observing the highlighted negative elements of greater than $30 \mathrm{mV}$. The contour plots have been used to interpret the matrices in Table 7 . Figure 16 shows the contour plots representing the difference between the induced voltages from the reference lines and the two short fault lines. The red starts represent the real locations of the faults. The highly negative regions have been represented by the color ranging from the light blue to black. Since there are two short faults on each board, the wider regions of the highly negative values in the contour plots can be observed. These regions give the information about the locations of the two short faults which can be detected by the elements of the matrix. These results have shown that two faults at time provide a clear visualization to locate the potential faults on the PCB lines compare to single fault at time. The two star locations are totally covered by the highly negative regions of the contour plots.

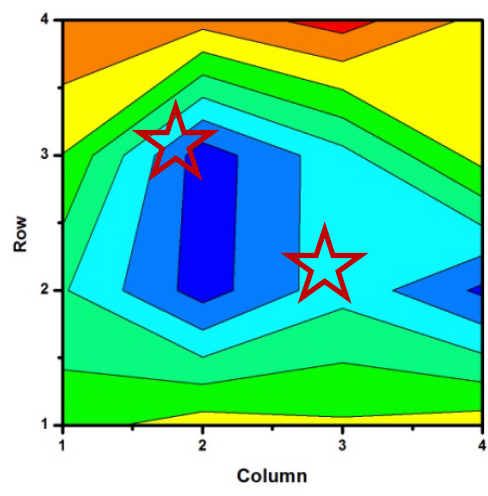

(a)

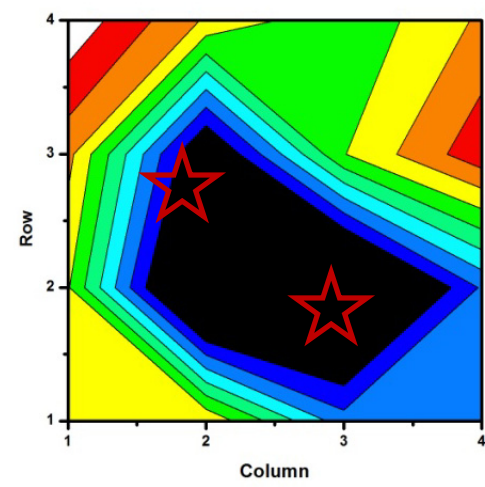

(c)

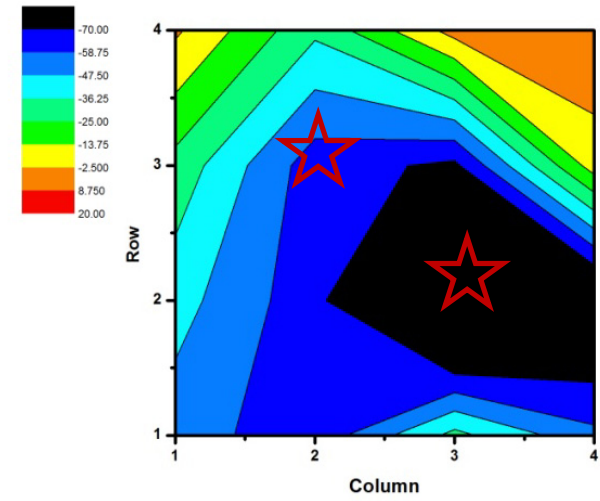

(b)
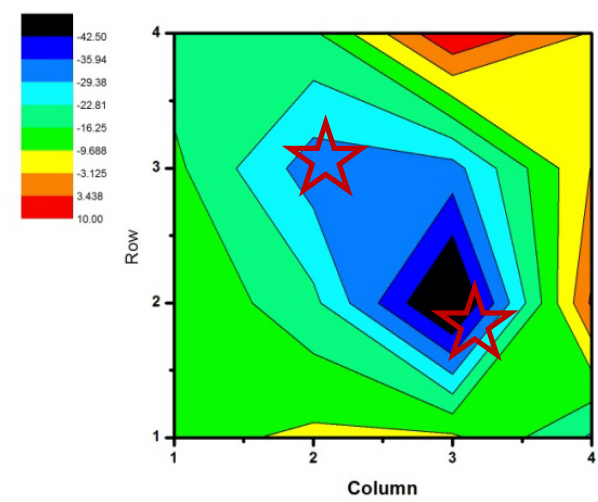

(d) 


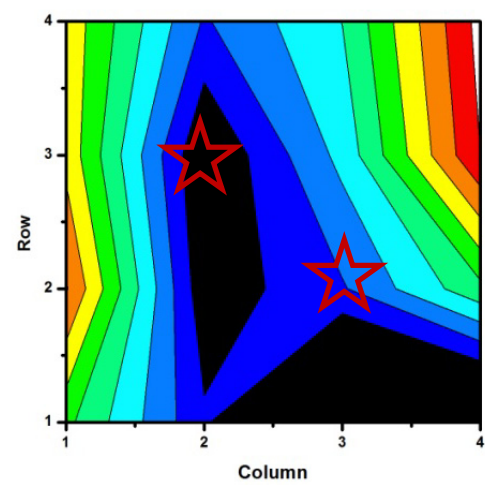

(e)
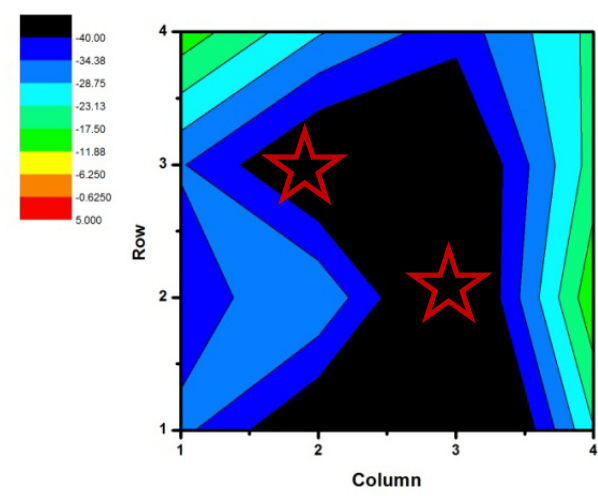

(f)

Figure 16. Contour map of the difference induced voltages between the fault free and two short faults boards: the lines of the width $300 \mu \mathrm{m}$ : (a) $1 \mathrm{~mm}$, (b) $2 \mathrm{~mm}$ and (c) $4 \mathrm{~mm}$ line spaces and the lines of the width $600 \mu \mathrm{m}$ : (d) 1 $\mathrm{mm}$, (e) $2 \mathrm{~mm}$ and (f) $4 \mathrm{~mm}$ line spaces

The last observation is to detect the two open faults on the lines of each board. Table 8 summarizes the difference between the induced voltages from fault free lines and two open faults on the lines.

Table 8. Difference of the induced voltages from fault free and two open faults boards

\begin{tabular}{|c|c|c|c|c|c|c|c|c|c|c|c|c|}
\hline \multirow{2}{*}{$\begin{array}{c}\text { Line } \\
\text { width }\end{array}$} & \multicolumn{12}{|c|}{$4 \times 4$ Array-coil sens or with $N=5$ turns (Ref-Open) for 2 open defects } \\
\hline & \multicolumn{4}{|c|}{ Line Space $=1 \mathrm{~mm}(\mathrm{mV})$} & \multicolumn{4}{|c|}{ Line Space $=2 \mathrm{~mm}(\mathrm{mV})$} & \multicolumn{4}{|c|}{ Line Space $=4 \mathrm{~mm}(\mathrm{mV})$} \\
\hline \multirow{4}{*}{$300 \mu \mathrm{m}$} & -20 & 22 & 7 & -9 & -7 & -5 & -2 & 7 & 9 & 2 & -16 & 11 \\
\hline & 7 & 6 & 36 & 34 & 9 & -3 & 36 & 37 & -5 & 5 & 26 & 27 \\
\hline & 7 & 40 & 49 & 7 & 9 & 37 & 28 & 12 & 14 & 45 & 44 & 19 \\
\hline & 21 & -10 & 0 & 14 & 3 & -7 & 9 & 15 & 7 & 3 & 14 & 0 \\
\hline \multirow{4}{*}{$600 \mu \mathrm{m}$} & 8 & 15 & -3 & 6 & -14 & -12 & -15 & -12 & 6 & -9 & 10 & 29 \\
\hline & 22 & 1 & 44 & 43 & 13 & -3 & 41 & 26 & 2 & 11 & 23 & 33 \\
\hline & -3 & 37 & 30 & 4 & 15 & 29 & 50 & 10 & -1 & 41 & 32 & 11 \\
\hline & 4 & -1 & 29 & 2 & 11 & -8 & 9 & 5 & 11 & -4 & 8 & 4 \\
\hline
\end{tabular}

In the case of two open faults at a time, the difference of induced voltages between fault free and faulty boards are highly positive. The high positive values occur around the potential defect points which are written in bold as shown in Table 8. Figure 17 illustrates these values of the matrices in the form of contour plots. From the contour plots the range of the high positive regions are in the ranges from orange to red to white color. These regions are the potential regions of the defect points. 


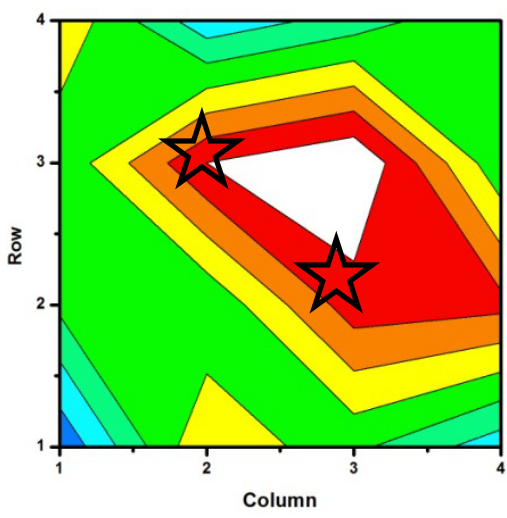

(a)

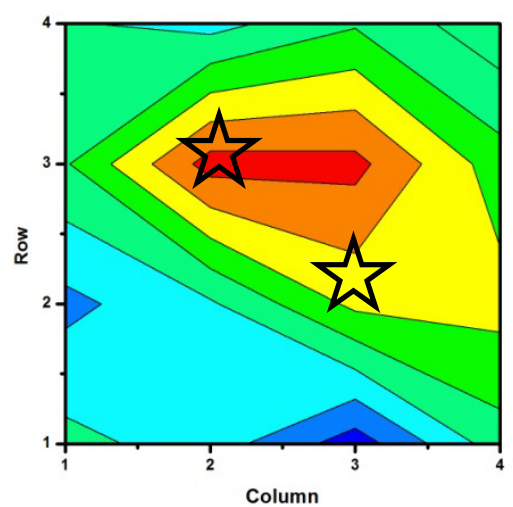

(c)

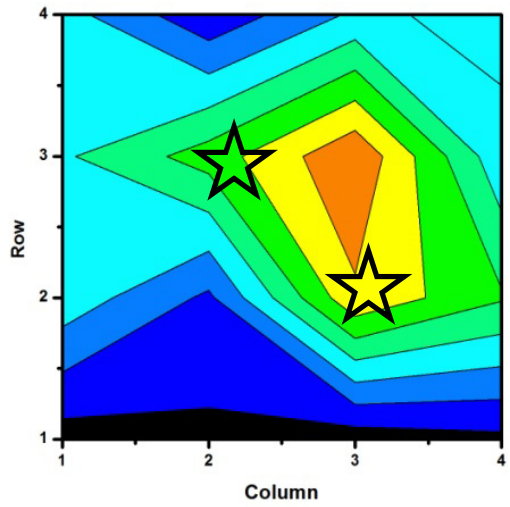

(e)
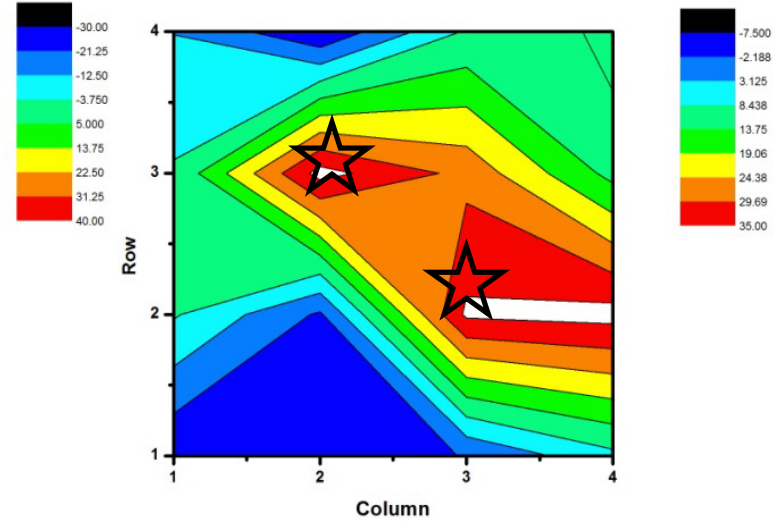

(b)
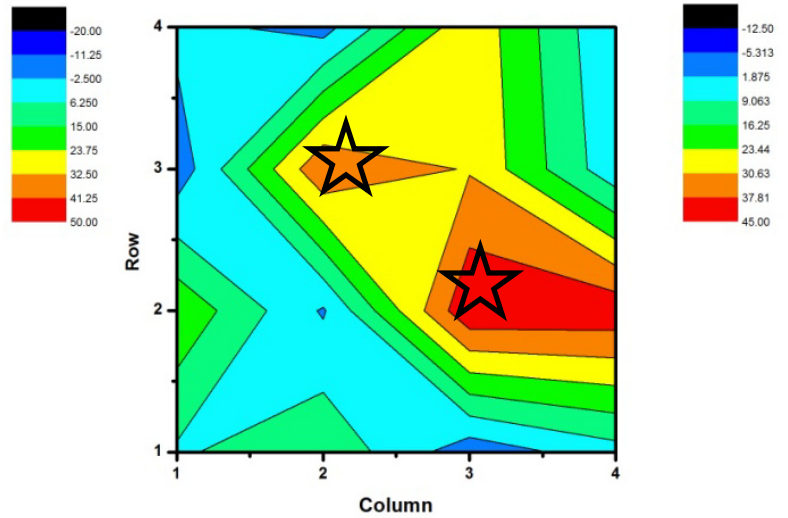

(d)
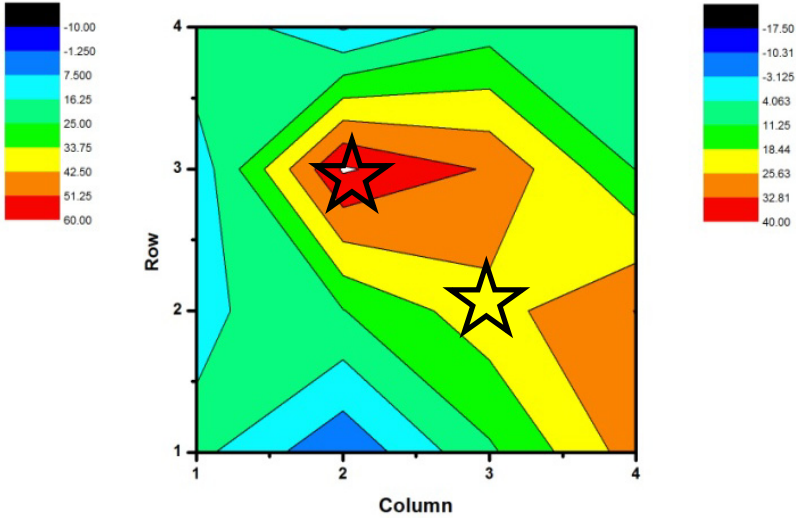

(f)

Figure 17. Contour map of the difference induced voltages between the fault free and two open faults boards: the lines of the width $300 \mu \mathrm{m}$ : (a) $1 \mathrm{~mm}$, (b) $2 \mathrm{~mm}$ and (c) $4 \mathrm{~mm}$ line spaces and the lines of the width $600 \mu \mathrm{m}$ : (d) 1 $\mathrm{mm}$, (e) $2 \mathrm{~mm}$ and (f) $4 \mathrm{~mm}$ line spaces

The experiments of PCB fault inspection have shown that the faulty boards induce higher or lower induced voltages compare to the induced voltages from the normal lines. The differences between the voltages from the fault free boards and faulty boards are recorded. The location of the faults can be identified by reading the contour plot color regions. From the observation, the PCB lines with the bigger line spacing of $4 \mathrm{~mm}$ produced a high difference between the induced voltages from the fault free boards and from the faulty boards. These differences have provided a clear observation to identify and locate the potential fault regions on the elements of 
the matrix as well as on the lines. Moreover, from the contour plots, two faults at a time could be noticed by having the wider regions of the highly negative or positive color ranges than a single fault. This is due to the higher number of faults which leads to higher changes of eddy current flow compared to one fault.

\section{Conclusion}

Printed circuit board (PCB) has played an important role as an electronic board to support and electrically connects the electrical components. With the advancement of the electronic circuit design technology, the reliability of the bare PCB on which the electronic components are mounted is very important to ensure a fully functioning system. The PCB inspection methods, such as optical inspection, and magnetic image analysis have been used to inspect the quality of PCBs. However, these methods are not sufficient to fully cover all of the possible faults as the density of the PCB traces become higher. In this work, the feasibility investigation of fault inspection using the magnetic field properties of PCB interconnect is experimented. The non-contact probe which is known as eddy current testing sensor (ECT) is realized. The sensor consists of the array of single coil of 5 turns is used to detect the changes of the induced magnetic field. This work has highlighted the proposed ECT sensor probe using the planar array-coils senor, to detect and locate the potential faults (short and open) on PCBs. The PCBs have been fabricated and tested for three cases: fault free (reference), short and open fault boards.

The study on PCB fault detection has been conducted in the magnetic shielded box. It has been shown that the short fault induces higher voltage levels around the fault area compared to the fault free lines. It leads to highly negative in difference between fault free and short lines induced voltage values. In contrast to the short fault, the open fault induces lower voltage levels around the fault area compared to the fault free lines. Thus, the difference between fault free and open lines induced voltage is highly positive in values. The potential fault locations can be located and observed by the highly positive or negative region of the contour plots from each matrix sensor. From the contour plots the PCB lines of width $300 \mu \mathrm{m}$ and the line spacing of $4 \mathrm{~mm}$ provide a better vision of highly positive or negative regions of potential faults. The experimental results have proved the feasibility investigation of short and open faults inspection by exploiting the magnetic field property of PCB interconnects which is detected by the eddy current testing probe. The testing fault patterns have been generated and analyzed.

\section{Acknowledgements}

This research work is supported by Universiti Teknologi PETRONAS (UTP) graduate assistantship (GA) scheme and Fundamental Research Grant Scheme (FRGS) by the Malaysian Ministry of Higher Education (MOHE).

\section{References}

Benedek, C., Krammer, O., Janoczki, M., \& Jakab, L. (2013). Solder Paste Scooping Detection by Multilevel Visual Inspection of Printed Circuit Boards. Industrial Electronics, IEEE Transactions on, 60(6), 2318-2331. http://dx.doi.org/10.1109/TIE.2012.2193859

Chomsuwan, K., Yamada, S., \& Iwahara, M. (2007a). Bare PCB Inspection System With SV-GMR Sensor Eddy-Current Testing Probe. Sensors Journal, IEEE, 7(5), 890-896. http://dx.doi.org/10.1109/JSEN.2007.894145

Chomsuwan, K., Yamada, S., \& Iwahara, M. (2007b). Improvement on Defect Detection Performance of PCB Inspection Based on ECT Technique With Multi-SV-GMR Sensor. Magnetics, IEEE Transactions on, 43(6), 2394-2396. http://dx.doi.org/10.1109/TMAG.2007.893480

Chomsuwan, K., Yamada, S., Iwahara, M., Wakiwaka, H., \& Shoji, S. (2005). Application of eddy-current testing technique for high-density double-Layer printed circuit board inspection. Magnetics, IEEE Transactions on, 41(10), 3619-3621. http://dx.doi.org/10.1109/TMAG.2005.855173

Dogaru, T., Smith, C. H., Schneider, R. W., \& Smith, S. T. (2004). Deep Crack Detection around Fastener Holes in Airplane Multi-Layered Structures Using GMR-Based Eddy Current Probes. AIP Conference Proceedings, 700(1), 398-405. http://dx.doi.org/10.1063/1.1711650

Enke, D., \& Dagli, C. (1997). Automated misplaced component inspection for printed circuit boards. Computers \& Industrial Engineering, 33(1-2), 373-376. http://dx.doi.org/10.1016/S0360-8352(97)00115-0

Gizopoulos, D. (2006). Advances in Electronic Testing: Challenges and Methodologies. The Netherlands: Springer. http://dx.doi.org/10.1007/0-387-29409-0

Grimberg, R., Udpa, L., Udpa, S., \& Savin, A. (2005). A Novel Rotating Magnetic Field Eddy Current Transducer for the Examination of Fuel Channels in PHWR Nuclear Power Plants. AIP Conference Proceedings, 760(1), 471-478. http://dx.doi.org/10.1063/1.1916713 
Guifang, D., Hongcui, W., Zhenyu, L., \& Yen-Wei, C. (2012). A Machine Learning-Based Framework for Automatic Visual Inspection of Microdrill Bits in PCB Production. Systems, Man, and Cybernetics, Part C: Applications and Reviews, IEEE Transactions on, 42(6), 1679-1689. http://dx.doi.org/10.1109/TSMCC.2012.2216260

Hara, Y., Akiyama, N., \& Karasaki, K. (1983). Automatic Inspection System for Printed Circuit Boards. Pattern Analysis and Machine Intelligence, IEEE Transactions on, PAMI-5(6), 623-630. http://dx.doi.org/10.1109/TPAMI.1983.4767453

Hara, Y., Doi, H., Karasaki, K., \& Iida, T. (1988). A system for PCB automated inspection using fluorescent light. Pattern Analysis and Machine Intelligence, IEEE Transactions on, 10(1), 69-78. http://dx.doi.org/10.1109/34.3868

Kacprzak, D., Taniguchi, T., Nakamura, K., Yamada, S., \& Iwahara, M. (2001). Novel eddy current testing sensor for the inspection of printed circuit boards. Magnetics, IEEE Transactions on, 37(4), 2010-2012. http://dx.doi.org/10.1109/20.951037

Mukhopadhyay, S. (2005). Novel Planar Electromagnetic Sensors: Modeling and Performance Evaluation. Sensors, 5(12), 546-579. http://dx.doi.org/10.3390/s5120546

Raj, B., Jayakumar, T., \& Thavasimuthu, M. (2007). Practical Non-destructive Testing. UK: Alpha Science International Ltd.

Shu-an, G., \& Fenglin, G. (2011, 20-21 Aug. 2011). A New Image Enhancement Algorithm for PCB Defect Detection. Paper presented at the Intelligence Science and Information Engineering (ISIE), 2011 International Conference on.

Uesaka, M., Nakanishi, T., Miya, K., Komatsu, H., Aoki, K., \& Kasai, K. (1995). Micro eddy current testing by micro magnetic sensor array. Magnetics, IEEE Transactions on, 31(1), 870-876. http://dx.doi.org/10.1109/20.364584

Ulaby, Fawwaz T. (2005). Electromagnetics for Engineers. Upper Saddle River, NJ: Pearson/Prentic Hall.

Yamada, S., Chomsuwan, K., Fukuda, Y., Iwahara, M., Wakiwaka, H., \& Shoji, S. (2004). Eddy-current testing probe with spin-valve type GMR sensor for printed circuit board inspection. Magnetics, IEEE Transactions on, 40(4), 2676-2678. http://dx.doi.org/10.1109/TMAG.2004.829254

Yamada, S., Chomsuwan, K., Hagino, T., Tian, H., \& Iwahara, M. (2005, 4-8 April 2005). Conductive micro-bead array detection by high-frequency eddy-current testing technique with SV-GMR sensor. Paper presented at the Magnetics Conference, 2005. INTERMAG Asia 2005. Digests of the IEEE International.

Yamada, S., Chomsuwan, K., \& Iwahara, M. (2006, 22-25 Oct. 2006). Application of Giant Magnetoresistive Sensor for Nondestructive Evaluation. Paper presented at the Sensors, 2006. 5th IEEE Conference on.

Yamada, S., Nakamura, K., Iwahara, M., Taniguchi, T., \& Wakiwaka, H. (2003). Application of ECT technique for inspection of bare PCB. Magnetics, IEEE Transactions on, 39(5), 3325-3327. http://dx.doi.org/10.1109/TMAG.2003.816765

\section{Copyrights}

Copyright for this article is retained by the author(s), with first publication rights granted to the journal.

This is an open-access article distributed under the terms and conditions of the Creative Commons Attribution license (http://creativecommons.org/licenses/by/3.0/). 